\title{
ESTABILIDADE DO SUCO TROPICAL DE ACEROLA (Malpighia emarginata D.C.) ADOÇADO ENVASADO PELOS PROCESSOS HOT-FILL E ASSÉPTICO
}

\author{
Claisa Andréa Silva de FREITAS ${ }^{2 *}$, Geraldo Arraes MAIA², \\ José Maria Correia da COSTA2, Raimundo Wilane de FIGUEIREDO², \\ Maria do Carmo Passos RODRIGUES ${ }^{2}$, Paulo Henrique Machado de SOUSA ${ }^{2}$
}

\begin{abstract}
RESUMO
Este trabalho objetivou avaliar a estabilidade do suco tropical de acerola adoçado, elaborado pelos processos hot fill (garrafas de vidro) e asséptico (embalagens cartonadas), com relação às alterações químicas e físico-químicas (pH, sólidos solúveis totais, acidez total titulável, cor, açúcares redutores, não redutores e totais), sensoriais e microbiológicas, durante 350 dias de armazenamento em condições similares às de comercialização $\left(28^{\circ} \mathrm{C} \pm 2{ }^{\circ} \mathrm{C}\right)$. Ao final do experimento, constatou-se que as amostras de suco de ambos os processos mantiveram uma adequada estabilidade microbiológica. O suco do processo hot fill teve maior aceitação global, enquanto o do processo asséptico manteve, ao final dos 350 dias, a aceitação inicial. As amostras do processo asséptico apresentaram inicialmente melhor sabor em comparação com as do processo hot fill, no entanto, as do processo hot fill mantiveram o sabor estável, enquanto o sabor do suco do processo asséptico teve menor aceitação ao longo do armazenamento. Ainda foram observadas, alterações químicas e físicoquímicas nos sucos de ambos os processos. Em geral, o processo hot fill foi o mais eficiente em manter a estabilidade do suco.

Palavras-chave: suco de acerola, hot fill, asséptico, vida de prateleira.
\end{abstract}

\section{SUMMARY}

STORAGE STABILITY OF SWEETENED TROPICAL ACEROLA JUICE PRESERVED BY HOT FILL AND ASEPTIC PROCESSES. This work aimed to evaluate the stability of the sweetened tropical juice of acerola, produced by the hot fill (glass bottles) and aseptic (packings carton) processes, regarding the chemical, physicochemical, sensorial and microbiological changes, during 350 days of storage $\left(28{ }^{\circ} \mathrm{C} \pm 2{ }^{\circ} \mathrm{C}\right)$. At the end of the experiment it was verified that the samples of both processes maintained an appropriate microbiological stability during the storage. The juice of the hot fill process presented a small increase in the global acceptance, while, the one of the aseptic process maintained, at the end of the 350 days, the same initial acceptance. Initially, the samples of the aseptic process presented better flavor, in comparison with the samples of the hot fill process, however, the juices of the hot fill process maintained stable flavor, while, that the flavor of the juices of the aseptic process was less accepted along the storage. There were still observed, chemical and physicochemical changes in the juices of both processes, showing the samples of the hot fill process greater stability. Keywords: acerola juice, hot fill, aseptic, shelf life.

\section{1 - INTRODUÇÃO}

As indústrias brasileiras processadoras de frutas tropicais processam cerca de 34,40 mil toneladas de acerolas por ano, o que equivale a $7,16 \%$ do total de frutas processadas por estas empresas. As acerolas processadas geram aproximadamente 18 mil toneladas de sucos e polpas por ano, concentrando-se esta produção nos Pólos de Açu/Mossoró, no Estado do Rio Grande do Norte, e da Região Metropolitana de Fortaleza, no Estado do Ceará, que são responsáveis por cerca de $34,7 \%$ e $33,9 \%$ desta produção, respectivamente [4]. Dentre os produtos elaborados por estas empresas, destaca-se o suco tropical de acerola.

O Suco Tropical de Acerola é a bebida não fermentada obtida pela dissolução em água potável, da polpa da acerola, por meio de processo tecnológico adequado. Este suco deve ser conservado por meios físicos adequados ou por

\footnotetext{
${ }^{1}$ Recebido para publicação em 14/9/2004. Aceito para publicação em 6/7/2006 (001485)

${ }^{2}$ Departamento de Tecnologia de Alimentos,

Universidade Federal do Ceará,

C. P. 12168, CEP 60356-000, Fortaleza (CE),

E-mail:frutos@ufc.br

* A quem a correspondência deve ser enviada
}

meio de conservadores químicos autorizados para sucos de frutas [8].

Os métodos mais utilizados pelas indústrias para a preservação de sucos de frutas tropicais consistem nos processos hot fill (garrafas de vidro) e asséptico (embalagens cartonadas).

Segundo MAIA, OLIVEIRA \& GUIMARAES [15], a elaboração de sucos pelo processo hot fill segue as etapas de seleção e lavagem dos frutos, extração do suco, formulação, homogeneização, desaeração, pasteurização em trocador de calor, enchimento a quente da embalagem (a aproximadamente $85{ }^{\circ} \mathrm{C}$ ), fechamento e resfriamento. O processo asséptico segue o mesmo fluxo de operações descrito acima até a etapa de pasteurização, após a qual o suco é resfriado (a aproximadamente $25{ }^{\circ} \mathrm{C}$ ) e envasado, sob condições assépticas, em embalagens previamente esterilizadas. Os produtos envasados por ambos os processos são armazenados em temperatura ambiente. De acordo com BARUFFALDI \& OLIVEIRA [5], a vida de prateleira desses sucos pasteurizados, adequadamente embalados e mantidos à temperatura ambiente, é superior a um ano.

Uma vez controlados os aspectos microbiológicos e enzimáticos, a estabilidade dos sucos de frutas está relacio- 
nada com a ocorrência de reações químicas complexas que comprometem suas qualidades sensoriais (aroma, sabor, cor, consistência, estabilidade da turbidez, separação das fases sólida- líquida, etc.) e que também acarretam perdas nutricionais [1].

A embalagem contribui para a qualidade final do suco, uma vez que tem a função de conter o produto de forma a protegê-lo das contaminações externas, quer sejam físicas, químicas ou biológicas, minimizando interações prejudiciais e prolongando a vida-de-prateleira desses sucos. Além disso, a embalagem possibilita o transporte e uma melhor apresentação dos produtos aos consumidores.

No Brasil, no segmento de mercado de sucos estáveis à temperatura ambiente, são usados tradicionalmente frascos de vidro, bem como as embalagens cartonadas de acondicionamento asséptico [6].

A embalagem cartonada é composta de seis camadas de diferentes materiais. Do interior para o exterior, possui duas camadas de polietileno que evitam qualquer contato do alimento com as demais camadas protetoras da embalagem. Em seguida, vem uma camada de alumínio, cuja função é evitar a passagem de oxigênio, luz e microrganismos, e uma quarta camada de polietileno. Uma quinta camada de papel confere resistência à embalagem e, finalmente, uma sexta camada de polietileno. Em linhas gerais, as embalagens são feitas de papel-cartão, plástico (polietileno de baixa densidade) e alumínio. O papel corresponde a $75 \%$, o plástico a $20 \%$ e o alumínio a $5 \%$. Antes do enchimento a embalagem é esterelizada, recebendo um banho de água oxigenada $\left(\mathrm{H}_{2} \mathrm{O}_{2}\right)$, seguido de secagem por um jato de ar quente a $270{ }^{\circ} \mathrm{C}[11]$.

A vida-de-prateleira é o período de tempo decorrido entre a produção e o consumo de um produto alimentício, no qual a aceitabilidade do produto pelo consumidor é mantida e verifica-se no produto um nível satisfatório de qualidade. Esta qualidade pode ser avaliada por parâmetros sensoriais (sabor, cor, odor e textura), por características gerais de aparência, pela carga microbiana, pela absorção de componentes da embalagem ou pelo valor nutricional [22].

Este trabalho objetivou avaliar a estabilidade do suco tropical de acerola adoçado, elaborado pelos processos hot fill (garrafas de vidro) e asséptico (embalagens cartonadas), com relação às alterações químicas, físico-químicas, sensoriais e microbiológicas, durante 350 dias de armazenamento em condições similares às de comercialização.

\section{2 - MATERIAL E MÉTODOS}

Para a realização dos experimentos foram utilizadas acerolas (Malphigia emarginata D.C.) maduras, frescas e sãs, colhidas manualmente na Região Metropolitana de Fortaleza-CE e transportadas para a unidade de processamento em caixas plásticas. O processamento do suco tropical de acerola adoçado foi realizado em empresa, próxima à área de colheita, de acordo com o fluxograma apresentado na Figura 1.

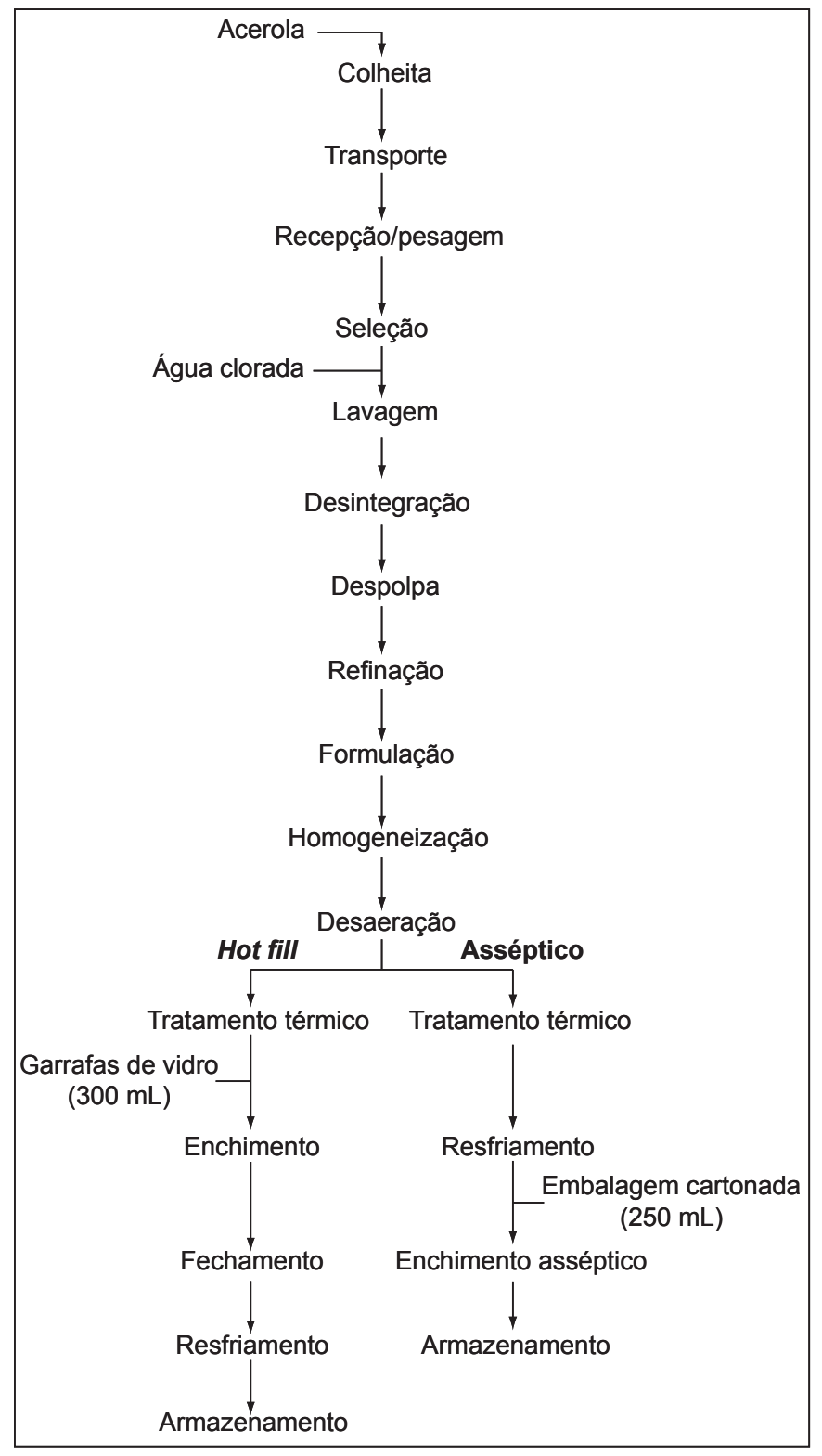

FIGURA 1 - Fluxograma de obtenção do suco tropical de acerola adoçado envasado pelos processos hot fill e asséptico.

No processo hot fill, os frutos foram selecionados em relação à sanidade, integridade física, uniformidade na coloração e maturação, e lavados por imersão em água clorada. Em seguida, os frutos passaram por uma despolpadeira onde se obteve o suco refinado, a partir do qual realizou-se a formulação (água, açúcar, 35\% de suco de acerola, acidulante ácido cítrico, citrato de sódio e estabilizante goma gelana), procedendo-se em seguida à homogeneização e posteriormente à desaeração. Na seqüência, realizou-se o tratamento térmico do suco, a $90{ }^{\circ} \mathrm{C}$ por $60 \mathrm{~s}$, seguido de enchimento a quente $\left(85^{\circ} \mathrm{C}\right)$ em garrafas de vidro $(300 \mathrm{~mL})$ e fechamento imediato por tampas metálicas. Após o fechamento, as garrafas foram resfriadas e rotuladas.

Os procedimentos para a elaboração do suco pelo processo asséptico foram os mesmos descritos para o hot fill, 
até a etapa do tratamento térmico, ressaltando-se que para a formulação deste suco foram utilizados apenas água, açúcar, 35\% de suco de acerola e o acidulante ácido cítrico. No processo asséptico, após o tratamento térmico, o suco foi resfriado e o enchimento foi realizado assepticamente a $25{ }^{\circ} \mathrm{C}$, em máquinas de envase asséptico, utilizando-se embalagens cartonadas (caixas de $250 \mathrm{~mL}$ ). As garrafas e as caixas cartonadas foram acondicionadas em caixas de papelão e armazenadas à temperatura ambiente $\left(28^{\circ} \mathrm{C} \pm 2{ }^{\circ} \mathrm{C}\right)$ para a avaliação da estabilidade por 350 dias.

Imediatamente após o processamento (tempo zero) e a intervalos regulares de 50 dias, foram realizadas análises de $\mathrm{pH}$ conforme AOAC [2], sólidos solúveis totais (em refratômetro de bancada, Analytikjena), acidez total titulável, açúcares redutores, não-redutores e totais de acordo com as metodologias do INSTITUTO ADOLFO LUTZ [14], cor de acordo com RANGANNA [21], além da análise sensorial de aceitação dos atributos sabor e aceitação global, utilizando-se o teste de escala hedônica estruturada de 9 pontos (9 = gostei muitíssimo; 5 = nem gostei, nem desgostei; 1 = desgostei muitíssimo) com 40 consumidores adultos, voluntários, como recomendado por MEILGAARD, CIVILLE \& CARR [19].

As análises microbiológicas de coliformes totais, coliformes fecais, bactérias aeróbias mesófilas, Salmonella sp, bolores e leveduras foram realizadas nos tempos zero, 150, 300 e 350 dias de armazenamento, seguindo-se a metodologia de APHA [3] e SILVA, JUNQUEIRA \& SILVEIRA [24].

Em cada tempo, foram coletadas três garrafas e três caixas de suco para a realização das análises químicas e fisico-químicas, além de duas caixas e duas garrafas para as análises microbiológicas e seis caixas e cinco garrafas para as análises sensoriais.

Os resultados das análises químicas, físico-químicas e sensoriais, obtidos durante os 350 dias de armazenamento dos sucos, foram avaliados estatisticamente, pelo programa Statistical Analysis System for Windows, versão 8 [23], por meio de análise de variância (ANOVA) e teste de Tukey ao nível de $5 \%(\mathrm{p}<0,05)$.

\section{3 - RESULTADOS E DISCUSSÃO}

Os resultados das análises químicas e físico-químicas encontram-se apresentados na Tabela 1 .

Os resultados encontrados para sólidos solúveis totais, acidez total titulável e açúcares totais estão de acordo com os padrões estabelecidos pela legislação para suco tropical de acerola adoçado [8], que estabelece valores mínimos de $10{ }^{\circ} \mathrm{Brix}, 0,20 \%$ em ácido cítrico e $7 \%$ de açúcares totais.

No suco elaborado pelo processo hot fill constatouse uma pequena redução de $\mathrm{pH}$, a partir dos 250 dias de armazenamento, enquanto que as amostras do processo asséptico apresentaram um leve aumento do $\mathrm{pH}$ entre os tempos zero e 50 dias, não apresentando diferença significativa ( $p>0,05$ ) nos tempos 50, 100, 150, 200 e 300 dias, no entanto, sofrendo uma redução para 3,11 ao final dos 350 dias de armazenamento. A incorporação apenas de ácido cítrico no suco do processo asséptico durante a formulação do produto pode justificar o menor $\mathrm{pH}$ desse suco no tempo zero, enquanto o pequeno aumento do seu $\mathrm{pH}$ durante o período de armazenamento pode ser atribuído à perda do ácido cítrico. As amostras do processo hot fill apresentaram maior $\mathrm{pH}$, possivelmente, devido à presença do estabilizante goma gelana em combinação com o efeito tampão do ácido cítrico + citrato de sódio, que pode ter sido minimizado com o tempo, visto que o $\mathrm{pH}$ tendeu a diminuir. CARVALHO \& GUERRA [9], avaliando a estabilidade do suco de acerola integral pasteurizado, envasado em garrafas de vidro, constataram que o $\mathrm{pH}$ das amostras manteve-se constante em 3,3, ao longo dos 150 dias de armazenamento à temperatura ambiente $\left(28{ }^{\circ} \mathrm{C} \pm 2{ }^{\circ} \mathrm{C}\right)$. Este valor está próximo ao encontrado por MATSUURA et al. [18], que determinaram um $\mathrm{pH}$ de 3,23 em suco de acerola integral comercial.

Os resultados iniciais de sólidos solúveis totais foram de $12{ }^{\circ} \mathrm{Brix}$ para as amostras dos dois processos, mantendo-se inalterados durante todo o período de armazenamento. A estabilidade dos sólidos solúveis totais durante o período de armazenamento também foi constatada por CARVALHO \& GUERRA [9], em suco integral de acerola acondicionado em garrafas de vidro e armazenados à temperatura am-

TABELA 1 - Resultados das análises químicas e físico-químicas do suco tropical de acerola adoçado envasado pelos processos hot fill $(H F)$ e asséptico (AS), em função do tempo de armazenamento de 350 dias.

\begin{tabular}{|c|c|c|c|c|c|c|c|c|c|c|c|c|c|c|}
\hline \multirow[t]{2}{*}{$\begin{array}{c}\text { Tempo } \\
\text { (dias) }\end{array}$} & \multicolumn{2}{|c|}{$\mathrm{pH}$} & \multicolumn{2}{|c|}{$\begin{array}{c}\text { Sólidos so- } \\
\text { lúveis totais } \\
\left({ }^{\circ} \text { Brix }\right)\end{array}$} & \multicolumn{2}{|c|}{$\begin{array}{c}\text { Acidez total } \\
\text { titulável ( } \% \text { ácido } \\
\text { Cítrico) }\end{array}$} & \multicolumn{2}{|c|}{$\begin{array}{c}\text { Cor } \\
(420 \mathrm{~nm})\end{array}$} & \multicolumn{2}{|c|}{$\begin{array}{c}\text { Açúcar redutor } \\
(\%)\end{array}$} & \multicolumn{2}{|c|}{$\begin{array}{l}\text { Açúcar não } \\
\text { redutor (\%) }\end{array}$} & \multicolumn{2}{|c|}{$\begin{array}{c}\text { Açúcar total } \\
(\%)\end{array}$} \\
\hline & $H F$ & AS & $H F$ & AS & $H F$ & AS & $H F$ & AS & $H F$ & AS & $H F$ & AS & $H F$ & AS \\
\hline Zero & $3,87^{b^{*}}$ & $3,03^{c}$ & $12,0^{\mathrm{a}}$ & $12,0^{a}$ & $0,23^{a}$ & $0,33^{a}$ & $0,079^{d}$ & $0,216^{b}$ & $4,82^{f}$ & $3,72^{\mathrm{e}}$ & $6,21^{a}$ & $7,84^{a}$ & $11,03^{b c}$ & $11,56^{a}$ \\
\hline 50 & $3,87^{b}$ & $3,19^{a}$ & $12,0^{\mathrm{a}}$ & $12,0^{a}$ & $0,23^{a}$ & $0,29^{b}$ & $0,067^{e}$ & $0,237^{a}$ & $5,42^{\mathrm{e}}$ & $6,90^{d}$ & $5,87^{a}$ & $4,62^{b}$ & $11,29^{a b}$ & $11,52^{a}$ \\
\hline 100 & $3,87^{\mathrm{b}}$ & $3,16^{a}$ & $12,0^{\mathrm{a}}$ & $12,0^{a}$ & $0,23^{a}$ & $0,26^{d}$ & $0,090^{\mathrm{bc}}$ & $0,159^{\text {de }}$ & $6,15^{\mathrm{d}}$ & $9,30^{c}$ & $4,76^{b}$ & $2,14^{c}$ & $10,91^{b c}$ & $11,44^{a}$ \\
\hline 150 & $3,84^{c}$ & $3,16^{a}$ & $12,0^{\mathrm{a}}$ & $12,0^{a}$ & $0,22^{a b}$ & $0,28^{b c}$ & $0,085^{\mathrm{cd}}$ & $0,155^{\mathrm{e}}$ & $7,38^{c}$ & $10,08^{b}$ & $3,32^{c}$ & $1,47^{d}$ & $10,70^{c}$ & $11,55^{a}$ \\
\hline 200 & $3,89^{a}$ & $3,16^{a}$ & $12,0^{\mathrm{a}}$ & $12,0^{a}$ & $0,22^{\mathrm{ab}}$ & $0,29^{b}$ & $0,084^{\mathrm{cd}}$ & $0,172^{d}$ & $8,80^{\mathrm{b}}$ & $11,29^{a}$ & $2,88^{c}$ & $0,00^{e}$ & $11,68^{a}$ & $11,29^{a}$ \\
\hline 250 & $3,82^{d}$ & $3,13^{b}$ & $12,0^{\mathrm{a}}$ & $12,0^{\mathrm{a}}$ & $0,19^{c}$ & $0,26^{d}$ & $0,084^{\mathrm{cd}}$ & $0,172^{d}$ & $9,87^{a}$ & $11,29^{a}$ & $1,72^{d}$ & $0,00^{\mathrm{e}}$ & $11,59^{a}$ & $11,29^{a}$ \\
\hline 300 & $3,82^{d}$ & $3,17^{\mathrm{a}}$ & $12,0^{\mathrm{a}}$ & $12,0^{a}$ & $0,23^{a}$ & $0,27^{\mathrm{cd}}$ & $0,093^{b}$ & $0,169^{\text {de }}$ & $9,87^{a}$ & $11,42^{a}$ & $1,92^{d}$ & $0,00^{\mathrm{e}}$ & $11,79^{a}$ & $11,42^{a}$ \\
\hline 350 & $3,73^{e}$ & $3,11^{\mathrm{b}}$ & $12,0^{\mathrm{a}}$ & $12,0^{a}$ & $0,21^{\mathrm{b}}$ & $0,27^{\mathrm{cd}}$ & $0,101^{a}$ & $0,198^{c}$ & $10,25^{a}$ & $11,47^{a}$ & $1,40^{d}$ & $0,00^{\mathrm{e}}$ & $11,65^{a}$ & $11,47^{a}$ \\
\hline
\end{tabular}

*médias seguidas de pelo menos uma mesma letra na mesma coluna, não diferem ( $\mathrm{p}>0,05)$ pelo teste de Tukey. 
biente $\left(28{ }^{\circ} \mathrm{C} \pm 2{ }^{\circ} \mathrm{C}\right)$; MATTA \& CABRAL [17], em suco de acerola clarificado envasado em garrafas de vidro e de polietileno tereftalato (PET) mantido sob refrigeração $\left(4{ }^{\circ} \mathrm{C}\right)$; e YAMASHITA et al. [25], em suco de acerola reconstituído e pasteurizado, acondicionado em garrafas de vidro e mantido à temperatura ambiente.

Os valores obtidos para acidez total titulável das amostras do processo hot fill não diferiram entre si $(\mathrm{p}>0,05)$ nos tempos zero, 50, 100, 150, 200 e 300 dias de armazenamento, apresentando, no entanto, uma leve redução ao final dos 350 dias. As amostras do processo asséptico apresentaram maior acidez total titulável no tempo zero, observando-se uma redução nos tempos 50 e 100 dias, porém não apresentando diferença significativa $(p>0,05)$ nos tempos 100, 250, 300 e 350 dias. A tendência de redução da acidez ao longo do tempo também foi evidenciada por CARVALHO \& GUERRA [9] e pode ser atribuída a oxidações dos ácidos orgânicos. As amostras do processo asséptico parecem ser mais susceptíveis a essas oxidações, sobretudo no início do armazenamento.

Ao final do período de armazenamento, foram evidenciados aumentos nos teores de açúcares redutores da ordem de $112,66 \%$ para o processo hot fill e de $208,33 \%$ para o processo asséptico. A hidrólise da sacarose pode justificar o aumento nos teores de açúcares redutores durante o período de armazenamento, uma vez que os sucos de ambos os processos foram acrescidos de açúcar (sacarose) durante a formulação. A hidrólise da sacarose no suco do processo asséptico foi mais efetiva, devido a sua maior acidez, justificando o maior aumento no teor de seus açúcares redutores quando comparado com o suco do processo hot fill.

Os teores de açúcares não-redutores para as amostras do processo hot fill variaram do tempo zero ao tempo 350 dias de 6,21 a 1,40, indicando uma redução da ordem de $77,46 \%$. No entanto, para as amostras do processo asséptico, observou-se no tempo 200 dias uma redução de $100 \%$ dos açúcares não-redutores iniciais. Para as amostras do processo asséptico, observou-se no tempo 200 dias a completa hidrólise da sacarose, justificando o desaparecimento dos açúcares não-redutores. No entanto, no processo hot fill, a contínua presença de açúcares nãoredutores deve-se à presença de sacarídeos, que não foram completamente hidrolisados devido à menor acidez do suco, somando-se a isto a presença de goma gelana, um polímero, que, durante a determinação de açúcares não-redutores, de acordo com a metodologia do INSTITUTO ADOLFO LUTZ [14], é hidrolisada em meio ácido a quente, contribuindo com o resultado dos açúcares não-redutores.

Comparando-se os valores obtidos nos tempos zero e 350 dias de armazenamento, observou-se para o processo hot fill um aumento no teor de açúcares totais da ordem de $5,62 \%$, enquanto que para o processo asséptico, os teores de açúcares totais não apresentaram diferença significativa $(\mathrm{p}>0,05)$ ao longo do período de armazenamento. Ao contrário do que foi observado nas amostras analisadas, CARVALHO \& GUERRA [9] constataram a manutenção da estabilidade dos açúcares totais durante 150 dias de arma- zenamento $\left(28{ }^{\circ} \mathrm{C} \pm 2{ }^{\circ} \mathrm{C}\right.$ ), em garrafa de vidro, do suco de acerola integral pasteurizado, o que também foi observado por MAIA et al. [16] avaliando uma bebida de baixa caloria à base de acerola (25\%), envasada em garrafa de vidro, pasteurizada e mantida por 120 dias a $25^{\circ} \mathrm{C}$.

Em sucos de frutas, o aparecimento de cor ao longo do tempo é uma medida indireta da concentração dos compostos polimérico-corados que se formam [13]. Para as amostras do processo hot fill, observou-se um aumento da absorbância, com o decorrer do armazenamento, indicando uma tendência ao escurecimento não-enzimático, o que pode ser verificado até mesmo pela avaliação visual. Ao contrário, as amostras do processo asséptico apresentaram uma redução da absorbância, ao final dos 350 dias do armazenamento, indicando uma perda de cor. Os sucos obtidos pelos dois processos, quando comparados, apresentaram diferenças na cor, desde o início do armazenamento. Essas diferenças possivelmente estão relacionadas à natureza da embalagem. O suco do processo asséptico pode ter interagido com a embalagem cartonada ou com resíduos de peróxido de hidrogênio, provavelmente contidos na embalagem, acarretando um suco mais escuro que o obtido pelo processo hot fill. COSTA [10] observou que para suco de caju, obtido pelos processos hot fill e asséptico, os resultados da análise de cor (pigmentos solúveis em água - $420 \mathrm{~nm}$ ) não apresentaram diferenças significativas $(\mathrm{p}>0,05)$ quando comparados aos valores obtidos no início e ao final de 350 dias de armazenamento $\left(28{ }^{\circ} \mathrm{C} \pm 2{ }^{\circ} \mathrm{C}\right)$. CARVALHO \& GUERRA [9], avaliando suco de acerola integral, pasteurizado e envasado em garrafas de vidro, evidenciaram, por observação visual, o aparecimento de pigmentos escuros no decorrer de 150 dias de armazenamento.

Os sucos obtidos pelos processos hot fill e asséptico, logo após o processamento (tempo zero) e durante os 350 dias de armazenamento, apresentaram contagens de bactérias aeróbias mesófilas, bolores e leveduras inferiores a $10 \mathrm{UFC} / \mathrm{mL}$, valores de coliformes totais (Coliformes a $35{ }^{\circ} \mathrm{C}$ ) e coliformes fecais (Coliformes a $45{ }^{\circ} \mathrm{C}$ ) inferiores a $3 \mathrm{NMP} / \mathrm{mL}$. Não foi detectada a presença de Salmonella $\mathrm{sp}$ nas amostras avaliadas. Os sucos atenderam aos padrões estabelecidos pela legislação federal vigente [7]. Portanto, as análises microbiológicas confirmaram a eficácia do tratamento térmico e a manutenção da qualidade microbiológica dos sucos durante o período de armazenamento.

Os resultados sensoriais estão apresentados na Tabela 2 . A aceitação global em função do tempo de armazenamento apresentou diferença significativa ao nível de 5\% para as amostras de ambos processos. Para o processo hot fill, os valores das médias das notas de aceitação global não diferiram entre si ( $\mathrm{p}>0$,05) nos tempos 50, 150, 200, $250 \mathrm{e}$ 350 dias. Observou-se um pequeno aumento na aceitação global das amostras do processo hot fill, contudo, para o processo asséptico, não houve diferença significativa ( $\mathrm{p}>0,05)$ entre as médias das notas nos tempos zero e 350 dias, indicando que não houve queda significativa da aceitação global ao final da vida de prateleira. 
TABELA 2 - Notas médias de aceitação global e da avaliação do sabor do suco tropical de acerola adoçado envasado pelos processos hot fill e asséptico, em função do tempo de armazenamento de 350 dias.

\begin{tabular}{cccccc}
\hline Tempo (dias) & \multicolumn{2}{c}{$\begin{array}{c}\text { Aceitação Global } \\
\text { (média das notas) }\end{array}$} & & \multicolumn{2}{c}{$\begin{array}{c}\text { Sabor } \\
\text { (média das notas) }\end{array}$} \\
\cline { 2 - 3 } \cline { 5 - 6 } & hot fill & Asséptico & & hot fill & Asséptico \\
\hline Zero & $4,2^{\mathrm{b} *}$ & $5,7^{\mathrm{a}}$ & & $4,2^{\mathrm{b} *}$ & $5,8^{\mathrm{a}}$ \\
50 & $5,5^{\mathrm{a}}$ & $5,3^{\mathrm{ab}}$ & & $5,2^{\mathrm{ab}}$ & $4,8^{\mathrm{ab}}$ \\
100 & $4,1^{\mathrm{b}}$ & $4,3^{\mathrm{bc}}$ & & $4,3^{\mathrm{b}}$ & $3,6^{\mathrm{bc}}$ \\
150 & $5,8^{\mathrm{a}}$ & $4,4^{\mathrm{abc}}$ & & $5,2^{\mathrm{ab}}$ & $3,7^{\mathrm{bc}}$ \\
200 & $5,3^{\mathrm{ab}}$ & $4,3^{\mathrm{bc}}$ & & $4,8^{\mathrm{ab}}$ & $3,4^{\mathrm{c}}$ \\
250 & $6,1^{\mathrm{a}}$ & $4,4^{\mathrm{abc}}$ & & $5,3^{\mathrm{ab}}$ & $3,3^{\mathrm{c}}$ \\
300 & $6,4^{\mathrm{a}}$ & $3,3^{\mathrm{c}}$ & & $5,8^{\mathrm{a}}$ & $3,1^{\mathrm{c}}$ \\
350 & $5,6^{\mathrm{a}}$ & $4,4^{\mathrm{abc}}$ & & $5,4^{\mathrm{ab}}$ & $3,7^{\mathrm{bc}}$ \\
\hline
\end{tabular}

${ }^{*}$ Médias seguidas de pelo menos uma mesma letra na mesma coluna, não diferem ( $\mathrm{p}>0,05$ ) pelo teste de Tukey.

Os resultados da avaliação do sabor (Tabela 2) do suco do processo hot fill não apresentaram diferença significativa $(p>0,05)$ entre si nos tempos 0, 50,100,150,200, 250 e 350 dias, todavia, para os sucos do processo asséptico, observou-se uma redução nos valores das notas atribuídas nos tempos zero, 50 e 100 dias, contudo, não diferiram ( $p>0,05)$ entre si nos tempos 100, 150, 200, 250, $300 \mathrm{e}$ 350 dias. As maiores notas conferidas ao sabor do suco do processo hot fill pode, em parte, ser devido à presença da goma gelana, uma vez que, segundo GOMAS [12], quanto menor a concentração de goma gelana utilizada mais destacado é o sabor em contato com a cavidade bucal.

A maior aceitação global no decorrer do armazenamento do suco obtido pelo processo hot fill deve-se provavelmente à maior aceitabilidade do seu sabor.

De um modo geral, os sucos de ambos os processos, hot fill e asséptico, apresentaram baixa aceitabilidade no decorrer de todo o período de armazenamento, o que pode ser observado pela maior ocorrência de notas quatro e cinco que equivalem, respectivamente, aos termos hedônicos nem gostei nem desgostei e desgostei ligeiramente.

\section{4 - CONCLUSÕES}

Os sucos tropicais de acerola adoçados elaborados pelos processos hot fill e asséptico mantiveram uma adequada estabilidade microbiológica durante o período de armazenamento.

Os sucos do processo hot fill apresentaram um pequeno aumento na aceitação global, enquanto os do processo asséptico mantiveram, ao final dos 350 dias, a mesma aceitação inicial. Os sucos do processo hot fill mantiveram o sabor estável, enquanto que o sabor dos sucos do processo asséptico foi menos aceito ao longo do armazenamento.

Alterações químicas e físico-químicas foram constatadas nos sucos de ambos os processos, no entanto as amostras do processo hot fill apresentaram maior estabilidade ao longo do período de armazenamento.
Em função das modificações observadas no produto envasado em embalagem cartonada, faz-se necessário avaliar, em estudos posteriores, a ocorrência de resíduos de peróxido de hidrogênio nesta embalagem, bem como a sua permeabilidade ao oxigênio, além da possibilidade da regeneração de enzimas no suco.

\section{5 - REFERÊNCIAS BIBLIOGRÁFICAS}

[1] ALVES, R. M. V.; GARCIA, E. E. C. Embalagem para Sucos de Frutas. In: Colet. ITAL, Campinas, SP, v. 23 , n. 2, p. 105-122, 1993.

[2] AOAC (ASSOCIATION OF OFFICIAL ANALITICAL CHEMISTRY - Official Methods of Analysis of the Association of Official Analytical Chemistry. 12 ed. Washington-DC: [S.1.], 1992.

[3] APHA (AMERICAN PUBLIC HEALTH ASSOCIATION). DOWNES \& ITO [coords.] . Compendium of Methods for the Microbiological Examination of Foods. 1.ed. Washington, DC: [S.1.], 2001. 676 p.

[4] ASTN (ASSOCIAÇÃO DAS INDUSTRIAS PROCESSADORAS DE FRUTOS TROPICAIS); APEX (PROGRAMA SETORIAL INTEGRADO DE PROMOÇÃO DE EXPORTAÇÕES DE SUCOS TROPICAIS). Brasília, 2001. Disponível em: <http://webm5.uol.com.br/cgi-bin/webmail. exe/messages $>$. Acesso em: 14 dez. 2003.

[5] BARUFFALDI, R.; OLIVEIRA, M. N. Conservação de Alimentos por Tratamento Térmico / Operações e Processos Unitários. In: BARUFFALDI, R.; OLIVEIRA, M. N. Fundamentos de Tecnologia de Alimentos. São Paulo, SP: Atheneu, v. 3, capítulo 3, p. 27-61 e capítulo 5, p. 83-122, 1998.

[6] BESERRA, F. J.; GUIMARÃES, A. C. L.. Embalagens para Sucos e Polpas. In: BESERRA, F.; GUIMARÃES, A. C. L. Curso de Tecnologia em Processamento de Sucos e Polpas Tropicais - Curso de especialização por tutoria à distância. Brasília, DF: ABEAS/UFC. 1998. Módulo 6.

[7] BRASIL, Resolução RDC n 12, de 02 de janeiro de 2001. Dispõe sobre os princípios gerais para o estabelecimento de critérios e padrões microbiológicos para alimentos. Agência Nacional de Vigilância Sanitária (ANVISA). Disponível em: <http://www.vigilanciasanitaria.gov. br/anvisa.html> . Acesso em: 12 fev. 2002.

[8] BRASIL. Ministério da Agricultura, Pecuária e Abastecimento. Instrução Normativa $n^{\circ} 12$, de 4 de setembro de 2003. Estabelece o Regulamento Técnico para fixação dos padrões de Identidade e Qualidade Gerais para o Suco Tropical e dá outras providências. Diário Oficial [da] República Federativa do Brasil, Brasília-DF, Ed. $\mathrm{n}^{\circ} 174$, de 9 de setembro de 2003.

[9] CARVAlho, I. T.; GUERRA, N. B. Suco de Acerola -Es tabilidade durante o armazenamento. In: SÃO JOSÉ, A. R.; ALVES, R. E. Cultura da Acerola no Brasil: produção de mercado. Vitória da Conquista: DFZ/UESB, p. 102-105, 1995.

[10] COSTA, M. C. O. Estudo da estabilidade do suco de caju (Anacardium occidentale L.) preservado pelos processos hot fill e asséptico. 1999, $80 \mathrm{f}$. Tese (Mestrado em Tecnologia de Alimentos) - Programa 
de Pós-Graduação do Departamento de Tecnologia de Alimentos, UFC, Fortaleza-CE. [s.n.], 1999.

[11] Embalagem Cartonada: transportando produtos sem refrigeração com segurança. [S.1.]: Pack. ano 6, n. 61, p. 22 , set. 2002 .

[12] GOMAS. Disponível em: <http://www.inf.ufsc.br/ $\sim$ taciano/temp/_Toc24698155>. Acesso em: $14 \mathrm{fev}$ 2004.

[13] GONZALEZ, C.; IBARZ, A.; ESPLUGAS, S.; VICENTE, M. Cinética del pardeamento no enzimático de zumos de frutas. [S.1.]: Alimentaria, v. 198, p. 53-60, diciembre 1988.

[14] INSTITUTO ADOLFO LUTZ. Normas analíticas do Instituto Adolfo Lutz: métodos químicos e físicos para análises de alimentos. São Paulo: Ed. São Paulo, 3 ed., v. 1, 1985. 533 p.

[15] MAIA, G. A.; OLIVEIRA, G. S. F.; GUIMARAES, A. C. L. Processamento Industrial. In: MAIA, G. A.; OLIVEIRA, G. S. F.; GUIMARAES, A. C. L. Curso de Tecnologia em Processamento de Sucos e Polpas Tropicais - Curso de especialização por tutoria à distância. Brasília-DF: ABEAS/UFC. 1998. Módulo 8.

[16] MAIA, G. A.; RITTER, U. G.; FIGUEIREDO, R. W.; OLIVEIRA, G. S. F.; JÚNIOR, J. C. G.; MONTEIRO, J. C. S. Obtenção e Avaliação de Bebida de Baixa Caloria à Base de Acerola (Malpighia emarginata D. C.). Revista Ciência Agronômica. Fortaleza: UFC, v. 34, n. 2, p. 233-240, 2003.

[17] MATTA, V.; CABRAL, L. Suco de acerola clarificado envasado em garrafas de vidro e de PET. In: Revista Engarrafador. [S. 1.]: Editora Aden, Ano XI, n. 103, p. 28-30, 2002.
[18] MATSUURA, F. C. A. U.; FOLEGATTI, M. I. S.; FERREIRA, D. C.; CARDOSO, R. L. Produção de geléia mista de maracujá e acerola com alto teor de vitamina C. In: XVII CONGRESSO BRASILEIRO DE FRUTICULTURA, 2002, Belém, Pará. Resumos...Belém, nov. 2002. 1 CD-ROM.

[19] MEILGAARD, M.; CIVILle, G. V.; CARR, B. T. Sensory Evaluation Techniques. 2ed. Florida-USA: CRC Press, 1991. $354 \mathrm{p}$.

[20] PENA, A. L. B. Hidrocolóides - usos em alimentos. Caderno de Tecnologia de Alimentos e Bebidas. p. 058-063. Disponível em: <http://www.revistafi.com. $\mathrm{br} /$ Main/revistas/ed_17/pdf/p\&da.pdf $>$. Acesso em: 12 jan 2004.

[21] RANGANA, M. Manual of analysis of fruit and vegetable products. New Delhi: MacGraw-Hill, 1997, p. 643.

[22] SARANTÓPOULOS, C. I. G. L.; OLIVEIRA, L. M.; CANAVESI, É. Alterações de Alimentos que resultam em Perda de Qualidade. In: SARANTÓPOULOS, C. I. G. L.; OLIVEIRA, L. M.; CANAVESI, É. Requisitos de Conservação de Alimentos em Embalagens Flexíveis. Campinas - SP: CETEA / ITA, capítulo 01, p. 1-22, 2001.

[23] SAS (Statistical Analysis System) for Windows, Versão 8,USA: Microsoft Corporation, 1999. 1 CD-ROM.

[24] SILVA, N.; JUNQUEIRA, V. C. A.; SILVEIRA, N. F. A. Manual de Métodos de Análise Microbiológica de Alimentos. São Paulo: Livraria Varela, $2^{\text {a }}$ ed., 2001. 229 p.

[25] YAMASHITA, F.; BENASSI, M. T.; TONZAR, A. C.; MORIYA, S.; FERNANDES, J. G. Produtos de acerola: estudo da estabilidade de vitamina C. Ciênc. Tecnol. Aliment., Campinas, v. 23, n. 1, p. 92-94, 2003. 